-Minireview.

\title{
The functional roles of feedback projections in the visual system
}

\author{
Tian-DeSHOU
}

Vision Research Laboratory, Center for Brain Science Research and School of Life Sciences, Fudan University, Shanghai 200433, China

(C) Shanghai Institutes for Biological Sciences, CAS and Springer-Verlag Berlin Heidelberg 2010

\begin{abstract}
Neurons in the nervous system make connections with ascending feedforward projections and descending feedback projections, as well as projections from neural structures at the identical hierarchical level. These neurons form extremely complicated neural networks and pathways. Compared with the role of the feedforward projection, much less is known concerning the functional roles of the feedback projection. Visual cortex is a good model for studying functional roles of cortical feedback projections which involve many high functions, such as attention, searching and cognition. The present review mainly focused on the functional roles of feedback projections in the visual system.
\end{abstract}

Keywords: feedback projection; feedforward projection; visual system; visual attention; oblique effect

\section{Parallel and hierarchical visual pathways in the brain}

Visual information from the outside world is first processed in the retina and then transferred to the dorsal lateral geniculate nucleus (LGN) in the thalamus of monkeys and cats. The LGN neurons are organized into different layers, each of which receives input only from one of the 2 eyes. In the monkey, there are 6 layers of neurons in the LGN: layers 1 and 2, which are called mango-cellular layers composed of large cells, and layers 3-6 which are called parvo-cellular layers composed of small cells. Functionally, parvo-cells are more sensitive to fine gratings of high contrast and color, while magno-cells are more sensitive to motion (velocity and direction) and rough gratings of low contrast, but not to color $^{[1-4]}$. Furthermore, in monkeys, there exist a small amount of cells called kino-cells in regions between the LGN layers.

Corresponding author: Tian-De SHOU

Tel: +86-21-65642355

E-mail: tdshou@fudan.edu.cn

Article ID: 1673-7067(2010)05-0401-10

Received date: 2010-05-16; Accepted date: 2010-06-11
These kino-cells are related to color vision, and they project to blobs in layers 2 and 3 of $\mathrm{V}^{[5,6]}$.

One of the most important progresses in cerebral cortex study in the last century is the discovery of 2 parallel pathways of visual information processing, i.e., the dorsal magnostream and the ventral parvo-stream in the monkey's visual cortex. These pathways involve more than 30 cortical areas and process visual information of motion/position and shape/ color, respectively ${ }^{[3,7-10]}$. Along each hierarchical stream, the sizes of receptive fields of cortical neurons gradually increase $^{[1-4,8,10]}$. Importantly, neurons in a given visual cortex receive not only feedforward input from the LGN and lower cortical area projections, but also feedback input from higher areas of visual cortex, as well as horizontal input from neurons of the local circuitry. Over the past half-century, much has been known about the roles of feedforward projection and local circuitry in the visual cortex. However, the feedback projections, which may be associated with many important functions such as attention, target search and other higher functions of the brain, are poorly understood and still need more investigations. 
In the visual system of monkeys, there are 3 (parvo-, mango- and kino-) pathways in parallel from the retina to the primary visual cortex V1 via the LGN, and then to other extrastriate cortices. In later stages, two streams of visual information processing pathway become significant due to the 2 gates that they respectively pass: area V4 and area MT (V5). Area V4 serves to be a gate of the ventral form/color stream, and area MT is the gate of the dorsal motion stream. Similarly, in the cat visual cortex, form and motion informations are processed by 2 streams gated by areas $21 \mathrm{a}$ and PMLS/PLLS, which are to a certain extent, equivalent to V4 and MT in the monkey, respectively ${ }^{[1]}$. In both species, almost all areas of the visual cortex have reciprocal connections, with few exceptions in the cat ${ }^{[12]}$, and both the feedforward and the feedback projections between cortical areas are mostly sent by pyramidal cells via glutamatergic excitatory synapses to the target cells ${ }^{[13,14]}$. However, the monosynaptic inhibitory synaptic potential between cortical areas of the same or the opposite hemisphere has not been reported ${ }^{[15]}$. Like the cortico-cortical connections, cortico-geniculate connections are predominantly excitatory ${ }^{[16,17]}$. Hierarchically, the "retina-LGN-V1-higher cortical areas" feedforward pathway provides the main driving force for the response properties of neurons ${ }^{[3,15,18-22]}$. Generally, the feedback projections from higher-level areas exert modulatory effects on the lower areas $^{[22-24]}$.

\section{The roles of cortico-thalamic feedback projection}

Layer 6 in the visual cortex is the location where cortical neurons send the corticofugal signals to the dorsal LGN of the thalamus. With synaptic distribution area and retinotopic regions much larger than those of retinal projection to the LGN, the feedback projections from cortical neurons are able to dynamically modulate the response patterns and spatiotemporal properties of the LGN neurons ${ }^{[25]}$.

The spiking trains of LGN neurons during period of visual stimulation are divided into 2 periods: burst and tonic modes. The burst firing in the LGN cells improves stimulus detectability and is thought to provide a high-security signal to focus the circuitry on the new feature, and to drive attention in the cortical activities. The tonic firing of cells in the
LGN has better linearity for accurately relaying information to visual cortex ${ }^{[26]}$. In the experiments of simultaneous dual recording from a LGN neuron and a cortical neuron, while feedback from layer 6 neurons of the primary visual cortex could be activated by local application of GABAb receptor antagonist CGP55845, Sillito and his colleagues found that the enhancement of feedback signals would lead to a significant shift in the burst/tonic ratio for $68 \%$ of LGN cells studied $(43 \%$ showed a shift from tonic to burst and $25 \%$ from burst to tonic) (Fig. 1) ${ }^{[25,27]}$. These findings indicate that changes of the responses of layer 6 cortical cells can clearly switch the firing mode of LGN cells. Thus, the role of corticothalamic feedback is that it may contribute to selective attention via its influence on geniculate firing mode. With the complex input from the natural visual world, selective adjustment of the transfer property of the LGN provides a means of alerting the visual system to salient change, and simultaneously optimizes its capacity to relay accurate information about what the system has worked.

Sillito's group have shown that the corticofugal projection from layer 6 of area V1 to the LGN enhances inhibitory mechanisms underlying length tuning, and is highly responsible for the length tuning of LGN cells. This suggests that the inhibitory effects derived from the corticofugal feedback exhibit characteristics of the response properties of orientation-tuned layer 6 cells ${ }^{[28]}$. Furthermore, they observed that the enhancement of the inhibitory surround leads to an increased sensitivity to orientation, direction, and temporal contrast, when 2 independent grating stimuli covered the center and surround regions of the receptive fields of LGN neurons, respectively. The sensitivity to difference in orientation of the LGN neurons is greatly reduced in the absence of feedback input ${ }^{[29-31]}$. Many experiments have demonstrated that the orientation-sensitive corticofugal feedback influences not only the center-surround interactions, but also the spatial frequency tuning of neurons in the LGN of cats ${ }^{[29,32]}$. Thus, the cortico-thalamic feedback enhances response precision in the visual system ${ }^{[33]}$.

Cortico-thalamus feedback also contributes to synchronization of geniculate neurons' activity. No synchronized response is found when 2 separate and neighboring recep- 

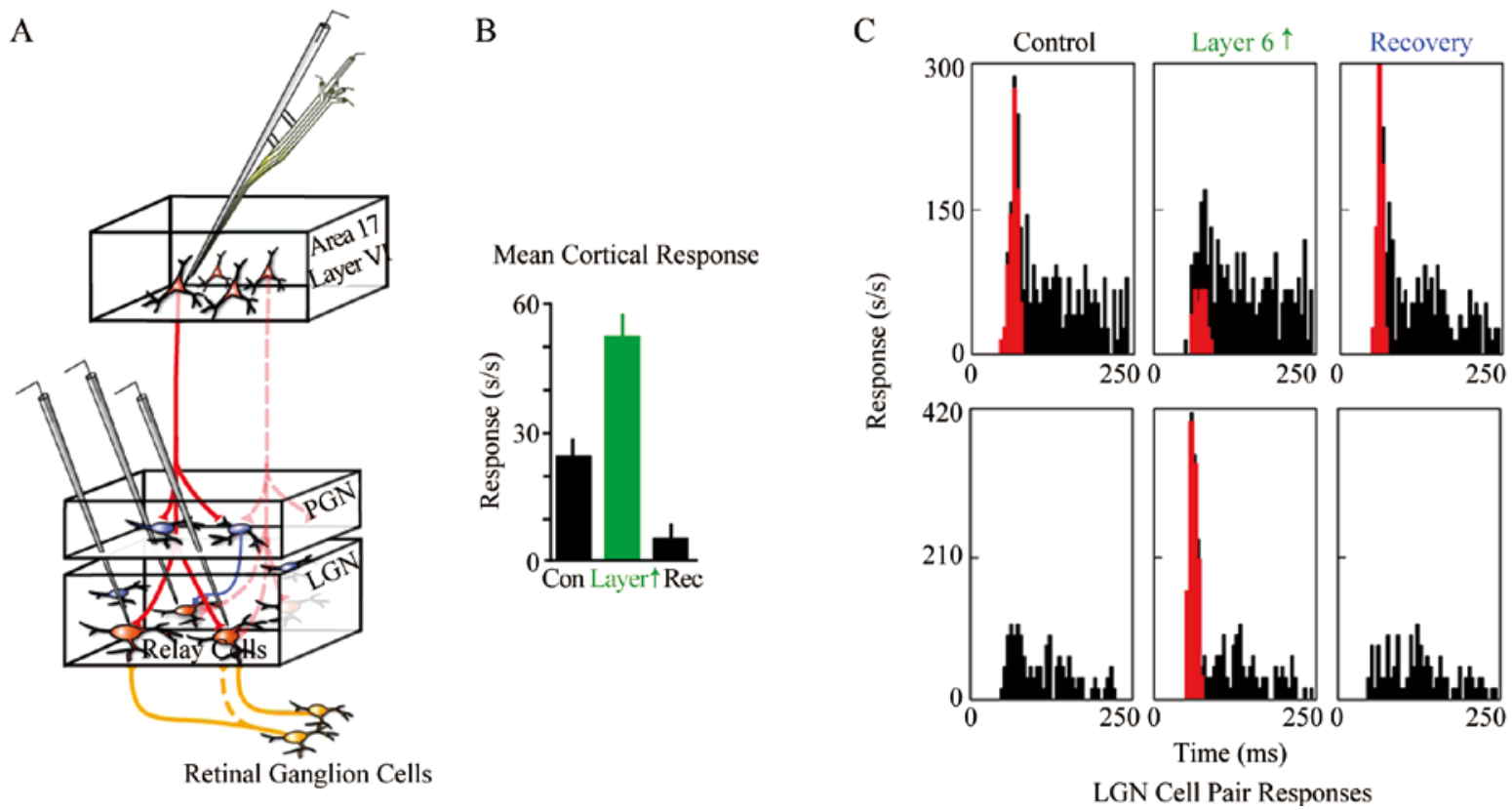

Fig. 1 Changes in the visual response mode of LGN neurons induced by local application of GABAb receptor antagonist CGP55845 into layer 6 of cortical area 17 (adopted from Sillito and Jones, 2004) ${ }^{[25]}$. A: An experimental diagram showing multimicropipette at layer 6 of the cortex for drug injection and single unit recording of visual response, and single pipettes at LGN for recording. B: Visual response amplitude of cortical layer 6 before, during and after excitation by CGP55845 application. C: Two LGN neurons shifting in visual response mode induced by the enhancement of feedback signal from layer 6 of area 17. Upper panel: the neuron response shifted from the burst mode to tonic mode. Lower panel: another neuron shifted from the tonic mode to burst mode.

tive fields of neurons in cat LGN are stimulated with a pair of flashing spots. However, as soon as a light bar simultaneously drifts across the 2 receptive fields, the 2 neurons respond in synchronization strongly. The synchronized responses would cease soon after ablation of the visual cortex ${ }^{[34]}$. This suggests that geniculate synchronization is generated via cortico-thalamic feedback mechanism, which may be involved in visual attention.

\section{Retinotopic relationship of feedback projections of the visual cortex}

Compared with the convergent feedforward projections, the feedback projections from high level cortical areas are distributed more diffused in the low level areas ${ }^{[21,35-37]}$. However, early studies have shown that the retinotopic relationship is better in the feedforward than in the feedback projecting areas, although the good retinotopic expression declines gradually with hierarchical feedforward pathways in visual cortex ${ }^{[21,38-40]}$. Therefore, feedback projections can be used to mix information from distant regions of the visual field. Stimulating areas 18 and 19 initiate responses of neurons in layers 2 and 3 of area 17 in a precise retinotopic way ${ }^{[41,56]}$. The most significant feedback effect can be found when the receptive fields of 2 neurons located at a higher area and a lower area, respectively, are overlapped in the visual field ${ }^{[42,43]}$. In the cat, the functional morphological distribution of the cortico-geniculate synaptic buttons exhibits a strong tendency that cortical cells in the contralateral eye dominant column mostly project to layer A of the LGN that solely receives the inputs from the contralateral eye, while cells in the ipsicontralateral eye dominant column mostly project to layer A1 that receives only input from the ipsilateral eye ${ }^{[44,57]}$.

\section{Excitatory influence of feedback projections in the visual cortex}

To study the roles of cortical feedback projections, the functional changes of neurons in the lower cortical areas are 
revealed by electrical or optical imaging techniques, when the higher cortical areas are affected by electrical stimulating, physical cooling, chemical activating or even lesioning. Stimulating the areas 18 and 19 of cat can induce the response increase of cortical neurons in layers 2 and 3 of area $17^{[45]}$. In rat, depolarization of neurons in area 17 can also be observed when the higher area is stimulated electrically ${ }^{[20]}$. Inactivation of area pLS can decrease visual responses of neurons in area 18 significantly ${ }^{[46]}$. Moreover, visual responses of neurons in areas 17 and 18 are declined by inactivation of area $21 \mathrm{a}^{[42,47]}$. In monkey, inactivation of area MT causes significant decreases in responses of neurons at areas V1, V2 and $\mathrm{V} 3^{[48,49]}$. These reports support the general view that cortical feedback projections exert an excitatory effect on neurons in the lower cortical areas. However, at the single cell level, inactivation of a cat's area 18 neuron causes not only response reduction, but sometimes also increase of those area 17 neurons, depending upon their receptive field locations, within the center or surround the receptive field of the given area 18 neuron $^{[50]}$. Thus, either increase or decrease in responses of layers 2 and 3 in area 17 was recorded when layers 2 and 3 in area 18 were locally inactivated ${ }^{[43]}$. Alonso et al. have found that $40 \%$ of the neurons in layer 5 of area 17 show increased responses to stimuli of low velocity when the corresponding region in layer 5 of area 18 is inactivated, suggesting that the preference to low velocities of neurons in layer 5 of area 17 is partially due to an inhibitory effect of area 18 that responds to high velocities ${ }^{[51,52]}$. The effects are strong and can often be observed when the inactivated area 18 neurons have overlapped receptive fields and the same response properties as those of recorded neurons in area 17. These are understandable because within a cortical area, both the pyramidal cells and the GABAergic inhibitory interneurons interact with each other at local circuits ${ }^{[53]}$.

\section{Feedback projections modulate tuning properties of neurons in the visual cortex}

The feedback input from higher levels of visual cortex finely modulates receptive field properties of neurons, in addition to facilitating responsiveness. Inactivation of layer 5 neurons in area 18 can cause significant alteration of half- widths of the orientation tuning curves in approximately $46 \%$ of the cells in layer 5 of area 17 in cats ${ }^{[52]}$. In contrast, the halfwidths of layer 2 and 3 neurons in area 17 are not affected by inactivation of layers 2 and 3 neurons in area $18^{[42,43]}$. These facts imply that feedback projections even from the same area may have different effects on the lower areas.

In the form information processing pathway, Wang et al. find that the shapes of orientation tuning curves of approximately half of the neurons in area 17 are sharply changed by inactivation of area 21 a, although the neurons' preferred orientation is not changed. Interestingly, little change is found in their direction selective and length selective curves in their single unit recording study ${ }^{[42]}$. On the other hand, Shou's group find that the feedback from area 21a significantly facilitates and improves neuronal activities of areas 17 and 18 in a spatial frequency-dependent manner ${ }^{[47]}$. In the motion information processing pathway, an optical imaging study has shown that inactivation of layer 5 in cat's area pLS influences direction selectivity of area 18 neurons and their direction map pattern, but not orientation pattern ${ }^{[46]}$. By using the same technique, Shou and his colleagues find that besides increasing the responsiveness of neurons in area 17, the feedback input from area PMLS can also modulate direction maps, but not orientation maps of neurons in area 17 of cats ${ }^{[54]}$. The question that whether the feedback signals from higher levels in the form or the motion information pathway solely modulate the corresponding properties of neurons in the lower levels still needs further investigation.

\section{Visual attention and feedback projections}

Attention to a visual stimulus increases the gain of neuron responses in most visual cortical areas ${ }^{[55,56]}$. Interestingly, these effects are strongest for low contrast stimuli and weak for high contrast stimuli ${ }^{[56,59]}$. Similarly, the feedback connections from MT to areas V1, V2 and V3 potentiate the strength of the inhibitory effect of the receptive field surround on the response elicited by stimulating the receptive field center. This effect is found to be specific to stimuli of low salience, such as a low contrast moving bar on a noisy background, but not to the stimuli of high salience ${ }^{[49,57]}$. This suggests a possibility that the mechanisms revealed by inactivating feed- 
back projections may be involved in an attention-directed modulation effect on the sensitivity of lower level areas. The first direct evidence supporting this idea is from Myiashita and his colleagues. Using a slit brain preparation, they distinguished activation by feedback projections of the frontal cortex, which transfers information about categorization signals of visual images, from that by feedforward projections in area IT neurons in monkey ${ }^{[58]}$.

The front eye field (FEF) in the frontal cortex is the primary cortical area that generates saccades and for controlling gaze shift through direct and indirect pathways to the superior colliculus, which plays a crucial role in the control of eye gaze shift ${ }^{[5,60]}$. Electrical stimulation of the FEF causes saccades to a particular position in the contralateral visual field. Damage of the FEF is usually temporary, but combined with the damage to the superior colliculus, it will produce a permanent deficit in generating voluntary gaze shift ${ }^{[61]}$. On the other hand, the lateral intraparietal area (LIP) of the parietal cortex plays a major role in the process of visual selection of gaze shift. Inactivation of neurons in area LIP dramatically reduces the frequency of movement towards the affected portions of the visual field, although it does not cause large deficits in the timing and accuracy of gaze shift, suggesting a visual neglect of stimuli in the affected region ${ }^{[62]}$. Clinically, damage of the parietal cortex in human also produces a neglect syndrome with similar deficits in attention.

\section{Visual psychology and feedback projections}

The oblique effect is a well-known psychological and behavioral phenomenon in humans and mammals that have a better visual ability in perceiving and discriminating horizontal and vertical contours than in oblique ones in the visual field ${ }^{[63-68]}$. This effect has been usually referred to as an event generated in the primary visual cortex, since more neurons there preferentially respond to the horizontal and vertical meridians than to the oblique ones ${ }^{[63-65,69-71]}$. Many similar reports have revealed less than $7 \%$ overexpression of cardinal contours than oblique contours in area 17 of ferrets, cats and humans ${ }^{[72-77]}$. However, the weak neuronal oblique effect seen in area 17 alone may not be sufficient to cause the psychological and behavioral effects. Recently, by using optical imaging, Shou and his colleagues have revealed that area $21 \mathrm{a}$ of the cat, which corresponds to $\mathrm{V} 4$ or $\mathrm{V} 3 \mathrm{~V}$ in the monkey, exhibits a much stronger oblique effect $[(24.0 \pm 3.9) \%$ overrepresentation of horizontal and vertical preference] than the primary visual cortex does $[(5.2 \pm 0.72) \%$ overrepresentation $]^{[78]}$, which can help explain the psychological or behavioral consequences. The fact that cat's area 21 a exhibits a much stronger oblique effect can be reasonable for explaining the psychological or behavioral consequences. Area 21a in the cat receives inputs mainly from area 17 and to a less extent from areas 18 and 19 separately ${ }^{[40,79]}$. Why and how the neurons in area 21a generate such a strong oblique effect remain to be elucidated.

Furthermore, Shou's group find that injection of glutamate or GABA into area 21a in cats significantly influences the visual response amplitude of neurons in area 17. Reversal activation of area 21a by glutamate significantly facilitates responses of neurons in area 17, while inactivation by GABA produces the opposite effect. Strikingly, the neuronal oblique effect in area 17 is largely enhanced by activation of neurons in area 21a, but decreased by inactivation of area 21 a via shifting the preferred orientation of some neurons in area 17 (Fig. 2) ${ }^{[80,81]}$. These findings support that the co-activation of areas $21 \mathrm{a}$ and 17 may greatly strengthen the neuronal basis of the psychological or behavioral oblique effect, indicating that feedback projection from higher level of cortical areas influence neurons' activities in the lower level that are even related to neuronal basis of psychological or behavioral phenomena.

Feedback signals either from mango-pathway or from parvo-pathway may re-enter the lower areas and co-activate the neurons there, even initiating synchronizing discharges of neurons in many cortical areas. The primary visual cortex has the finest retinotopic representation of the visual field and receives a large number of projections from higher areas, where the motion and form/color signals are separately processed in the visual system. Thus, it is possible to provide a platform for spatio-temporal integration of visual information in the primary visual cortex via neuronal co-activation or synchronization that is presumably necessary for perceiving an object, although this hypothesis needs further studies. 
A

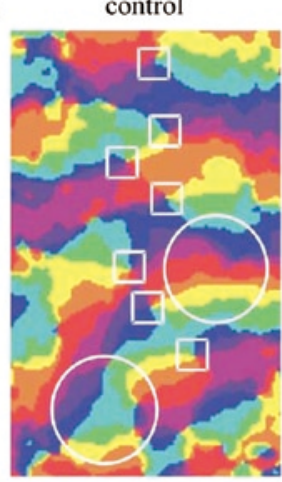

E

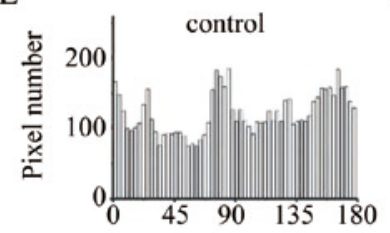

B

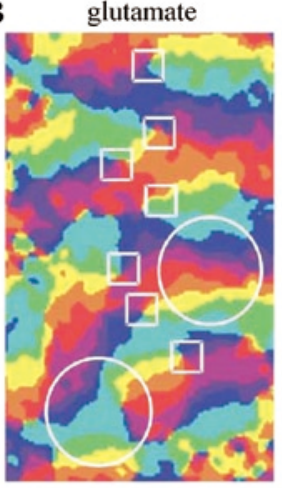

$\mathrm{F}$

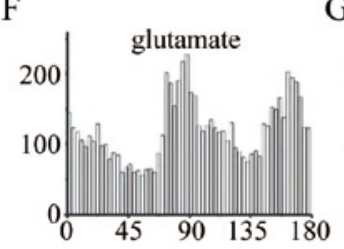

C

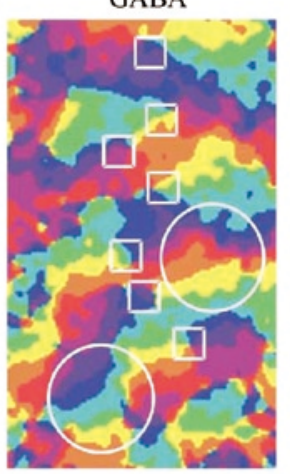

G

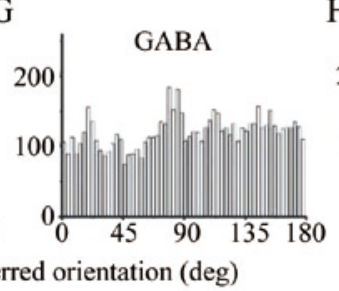

D

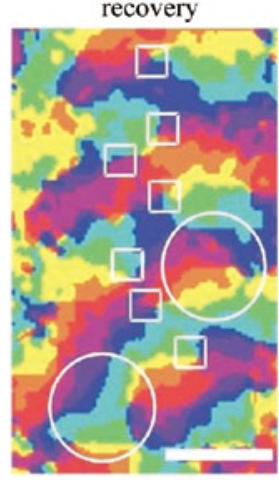

H

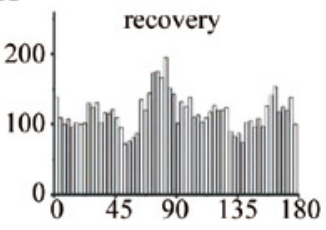

I

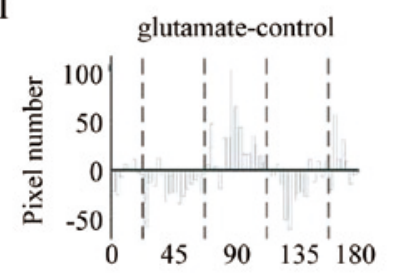

$\mathbf{J}$

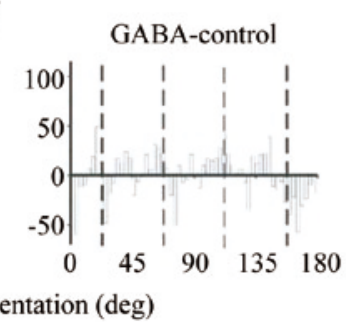

K

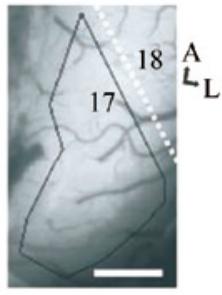

Fig. 2 Enhancement of neural oblique effect in visual cortical area 17 induced by feedback of cortical area 21 a in the cat (adopted from Liang et al., 2007 $\left.{ }^{[80]}\right)$. A-D: Functional orientation columns of area 17 revealed by optical imaging of intrinsic signals before (A), during glutamate (B) and GABA (C) application, and in recovery (D), respectively. Scale bar=1 $\mathbf{m m}$. E-H: Preferred orientation distribution histograms of all pixels in A-D, respectively. Note that more pixels in area 17 preferred to horizontal and vertical orientations $\left(0^{\circ}, 180^{\circ}\right.$ and $\left.90^{\circ}\right)$ than the oblique $\left(45^{\circ}\right.$ and $\left.135^{\circ}\right)$ in control $\left(\mathrm{E}^{\circ}\right)$ and recovery $(\mathrm{H})$, showing the oblique effect, which was significantly enhanced by glutamate excitation (F) and declined by $G A B A$ inhibition $(G)$ in area. $I$ and $J$ : Net change in preferred orientation distribution histograms caused by application of glutamate (I) and GABA (J) in area 21 a. Some pixels that preferred to the oblique were shifted to the horizontal and vertical by glutamate application (I), and some pixels that preferred to horizontal and vertical were shifted to the oblique by GABA application (J). Positive number denotes newly increased pixels, and negative number is for pixels that disappear. K: Surface vessel map of the visual cortex. White dot line denotes the border between areas 17 and 18 , and black line indicates the region of interest in the study. A, anterior; L, lateral. Scale bar $=1 \mathrm{~mm}$.

More interestingly, multisensory convergence of inputs from auditory and polysensory cortices and multimodal integration have been found in the primary visual cortex ${ }^{[22,83]}$. These findings may be related to the recent psychophysical report of sound-induced illusory flash effect, in which a human subject perceives a single flash as two when the single flash is accompanied by 2 auditory beeps ${ }^{[84]}$. A similar visual illusion can also be produced by touch stimuli ${ }^{[85]}$.

Singer points out that neuronal combination related to the synchronized discharges of neurons in the brain conforms to the Gestalt criteria ${ }^{[86]}$. According to the principles of Gestalt psychology, pattern features of an object tend to be organized together to form a subjective perception that human perceives by using those features of neighboring, similarity, continuation, and common fate ${ }^{[87]}$. Engel and his colleagues provide evidence supporting that the interaction between neurons at different levels of cortical areas meets Gestalt criteria of continuity and common fate ${ }^{[88]}$. In their 
experiments, two cortical cells were simultaneously recorded respectively from areas PMLS and 17 whose receptive fields were spatially separated and aligned, with an identical preferred orientation. When a long moving bar was drifting in the preferred direction across the 2 receptive fields, strong synchronized responses were elicited. Two short bars moving simultaneously in the preferred direction evoked relatively weak, but significant synchronized responses. Interestingly, the synchronized response disappeared completely when the bars were moving in opposite directions.

\section{Conclusion}

Recent research on the functional roles of feedback projections has been developed rapidly in the visual system. More than 30 reciprocally connected cortical areas in the visual system provide an ideal model for elucidating the important roles of feedback projections, especially when much has been known about the roles of feedforward projections in the visual pathway after 3 decades of research. Feedback signals from multiple cortical areas interact with feedforward signals and horizontal projections in a local circuitry, and precisely shape response properties of neurons in a given cortical area along the hierarchical visual pathway. The relative contribution of these signals remains unclear at the synaptic level. In addition, the roles of feedback signals in modulating gain control of neurons in the visual system need to be investigated in detail.

On the other hand, whether the feedback signals from mango- and parvo-pathways have different preferences and how they interact with each other to modulate the lower cortical areas remain still elusive. Furthermore, whether the functions of feedback signals directly from distal areas differ from that from near areas in information processing needs to be further determined.

Feedback projections play very important roles in descending signals that are related to higher-order processing functions, such as visual attention, searching and controlling gaze. Elucidating these aspects is a difficult and longlasting task, due to the complexity of anatomy and function of the brain. Certainly, novel research tools, especially noninvasive techniques with high resolution need to be developed for in vivo psychological and behavioral studies in human and monkey. New imaging techniques, such as functional MRI, optical imaging and two-photo confocal imaging, combined with largely developed substances for labeling neurons or axons, have been showing great power in the studies.

Acknowledgements: This work was supported by the National Natural Science Foundation of China (No. 90208013), Shanghai Leading Academic Project \#B111 and "211"Project of Ministry of Education of China.

\section{References:}

[1] Livingstone MS, Hubel DH. Psychophysical evidence for separate channels for the perception of form, color, movement, and depth. J Neurosci 1987, 7: 3416-3468.

[2] Zeki S. The visual image in mind and brain. Sci Am 1992, 267: 69-76.

[3] Ungerleider LG, Pasternak T. Ventral and dorsal cortical processing streams, in: Visual Neuroscience. Cambridge, MA: MIT Press, 2004: 541-562.

[4] Shou T. Brain Mechanisms of Visual Information Processing. Shanghai: Shanghai Scientific \& Technological Education Publishing House, 1997.

[5] Casagrande VA, Ding Y, Boyd JD. The morphology of LGN axons from different $\mathrm{K}$ layers in V1 of macaque monkey. Soc Neurosci Abstr 1997, 23: 2361.

[6] Ding Y, Casagrande VA. The distribution and morphology of LGN K pathway axons within the layers and CO blobs of owl monkey V1. Vis Neurosci 1997, 14: 691-704.

[7] Ungerleider LG, Mishkin M. Two cortical visual systems, in: Goodale MA and Mansfield RJW (eds.), Analysis of Visual Behavior. Cambridge: MIT Press, 1982: 549-586.

[8] DeYoe EA, Van Essen DC. Concurrent processing streams in monkey visual cortex. Trends Neurosci 1988, 11: 219-226.

[9] Merigan WH, Maunsell JH. How parallel are the primary visual pathways? Annu Rev Neurosci 1993, 16: 369-402.

[10] Van Essen DC, Felleman DJ, DeYoe EA, Olavarria J, Knierin J. Modular and hierarchical organization of extrastriate visual cortex in the macaque monkey. Cold Spring Harb Symp Quant Biol 1990, 55: 679-696.

[11] Burke W, Dreher B, Wang C. Selective block of conduction in Y optic nerve fiberes: significance for the concept of parallel processing. Eur J Neurosci 1998, 10: 8-19.

[12] Meyer G, Albus K. Spiny stellates as cells of origin of association 
fibres from area 17 to area 18 in the cat's neocortex. Brain Res 1981, 210: 335-341.

[13] Lund JS, Wu CQ. Local circuit neurons of macaque monkey striate cortex: IV. Neurons of laminae 1-3A. J Comp Neurol 1998, 384: 109-126.

[14] Johnson RR, Burkhalten A. Microcircuitry of forward and feedback connections within rat visual cortex. J Comp Neurol 1996, 368: 383- 398 .

[15] Bullier J. Communications between cortical areas of the visual system. In: The Visual Neurosciences, 2004, 1: 522-540.

[16] Montero VM. A quantitative study of synaptic contacts on internnections and relay cells of the cat lateral geniculate nucleus. Exp Brain Res 1991, 86: 257-270.

[17] Weber A, Kalil RE, Behan M. Synaptic connections between corticogeniculate axons and interneurons in the dorsal lateral geniculate nucleus of the cat. J Comp Neurol 1989, 289: 156164.

[18] Domenici L, Harding GW, Burkhalter A. Patterns of synaptic activity in forward and feedback pathways within rat visual cortex. J Neurophysiol 1995, 74: 2649-2664.

[19] Douglas RJ, Martin KA. A functional microcircuit for cat visual cortex. J Physiol 1991, 440: 735-769.

[20] Shao Z, Burkhalter A. Different balance of excitation and inhibition in forward and feedback circuits of rat visual cortex. J Neurosci 1996, 16: 7375-7365.

[21] Salin PA, Bullier J. Corticocortical connections in the visual system: structure and function. Physiol Rev 1995, 75: 107-154.

[22] Burke W, Dreher B, Wang C. Selective block of conduction in Y optic nerve fibers: significance for the concept of parallel processing. Eur J Neurosci 1998, 10: 8-19.

[23] Payne BR, Lomber SG. Quantitative analyses of principal and secondary compound parieto-occipital feedback pathways in cat. Exp Brain Res 2003, 152: 420-433.

[24] Lamme VA, Super H, Spekreijse H. Feedforward, Horizontal and feedback processing in the visual cortex. Curr Opin Neurobiol 1998, 8: 529-535.

[25] Sillito AM, Jones HE. Feedback systems in visual processing. In: Visual Neuroscience. Camridge, MA: MIT Press, 2004: 609-624.

[26] Sherman SM. Tonic and burst firing: dual modes of thalamocortical relay. Trends Neurosci 2001, 24: 122-126.

[27] Wang W, Jones HE, Andolina IM, Salt TE, Sillito AM. Functional alignment of feedback effects from visual cortex to thalamus. Nat Neurosci 2006, 9: 1330-1336.

[28] Murphy PC, Sillito AM. Corticofugal feedback influences the generation of length tuning in the visual pathway. Nature 1987, 329: 727-729.

[29] Sillito AM, Cudeiro J, Murphy PC. Orientation sensitive elements in the corticofugal influence on center-surround interac- tions in the dosal lateral geniculate nucleus. Exp Brain Res 1993, 93: 6-16.

[30] Sillito AM, Andolina IM, Jones HE. The processing by cells in the cat $\mathrm{dLGN}$ of the relative phase between center and surround. Invest Ophthalml Vis Sci 1999, 40: 3380.

[31] Sillito AM, Jones HE. Functional organization influencing neurotransmission in the lateral geniculate nucleus. In: Steriade M, Jones EG, McCormick DA (eds). Thalamus, vol 2: experimental and clinical aspects. Amsterdam: Elsevier, 1997: 1-52.

[32] Cudeiro J, Sillito AM. Spatial frequency tuning of orientationdiscrimination-sensitive corticofugal feedback to the cat lateral geniculate nucleus. J Physiol 1996, 481-492.

[33] Andolina IM, Jones HE, Wang W, Sillito AM. Cortico-thalamic Feedback Enhances Stimulus Response Precision in the Visual System. Proc Natl Acad Sci U S A 2007, 104: 1685-1690.

[34] Sillito AM, Jones HE, Gerstein GL, West DC. Feature-linked synchronization of thalamic relay cell firing induced by feedback from the visual cortex. Nature 1994, 366: 479-482.

[35] Sipp S, Grant S. Organization of reciprocal connections between area 17 and the lateral suprasylvian area of cat visual cortex. Vis Neurosci 1991, 6: 339-355.

[36] Shipp S, Zeki S. The organization of connections between areas $\mathrm{V} 5$ and V1 in macaque monkey visual cortex. Eur J Neurosci 1989, 1: 308-331.

[37] Zeki S, Shipp S. The functional logic of cortical connections. Nature 1988, 335: 311-317.

[38] Sherk H. Location and connections of visual cortical areas in the cat's suprasylvian sulcus. J Comp Neurol 1986, 247: 1-31.

[39] Symond LL, Rosenquist AC. Corticocortical connections among visual areas in the cat. J Comp Neurol 1984, 229: 1-38.

[40] Dreher B. Thalamocortical and corticocortical interconnections in the cat visual system: relation to the mechanisms of information processing, In: Pettigrew JD, Sanderson KL, Levick RM (eds.), Visual Neuroscience. Cambridge Univ Press, Cambridge, UK, 1986.

[41] Bullier J, McCourt ME, Henry GH. Physiological studies on the feedback connections to the striate cortex from cortical areas 18 and 19 of the cat. Exp Brain Res 1988, 70: 90-98.

[42] Wang C, Waleszczyk WJ, Burke W, Dreher B. Modulatory influence of feedback projections from area 21a on neuronal activities in striate cortex of the cat. Cereb Cortex 2000, 10: 12171232.

[43] Martinez-Conde S, Cudeiro J, Kenneth J, Grieve KL, Rodriguez $\mathrm{R}$, Rivadulla $\mathrm{C}$, et al. Effect of feedback projections from area 18 layers $2 / 3$ to area 17 layers $2 / 3$ in the cat visual cortex. J Neurophysiol 1999, 82: 2667-2675.

[44] Murphy PC, Sillito AM. Functional morphology of the feedback pathway from area 17 of the cat visual cortex to the lateral 
geniculate nucleus. J Neurosci 1996, 16: 1180-1192.

[45] Bullier J, McCount ME, Henry GH. Physiological studies on the feedback connection to the striate cortex from cortical areas 17 and 18 of the cat. Exp Brain Res 1988, 70: 90-98.

[46] Galuske RA, Schmidt KE, Goebel R, Lomber SG, Payne BR. The role of feedback in shaping neuronap representations in cat visual cortex. Proc Natl Acad Sci U S A 2002, 99: 17083-17088.

[47] Huang L, Chen X, Shou T. Spatial frequency-dependent feedback of visual cortical area 21a modulating functional orientation column maps in areas 17 and 18 of the cat. Brain Res 2004, 998: 194-201.

[48] Hupe JM, James AC, Girard P, Lombber SG, Payne BR, Bullier J. Feedback connections act on the early part of the responses in monkey visual cortex. J Neurophysiol 2001, 85: 134-145.

[49] Hupe JM, James AC, Girard P, Lombber SG, Payne BR, Bullier J. Cortical feedback improves discrimination between figure and background by V1, V2 and V3 neurons. Nature 1998, 349: 784787.

[50] Bullier J, Hupe JM, James A, Girard P. Functional interactions between areas V1 and V2 in the monkey. J Physiol Paris 1996, 90: 217-220.

[51] Alonso JM, Cudeiro J, Perez R, Gonzalez F, Acuna C. Influence of layer $\mathrm{V}$ of area 18 of the cat visual cortex on responses of cells in layer V of area 17 to stimuli of high velocity. Exp Brain Res 1993, 93: 363-366.

[52] Alonso JM, Cudeiro J, Perez R, Gonzalez F, Acuna C. Orientational influences of layer $\mathrm{v}$ of visual area 18 upon cells in layer V of area 17 in the cat cortex. Exp Brain Res 1993, 96: 212220.

[53] Nowak LG, James AC, Bullier J. Corticocortical connections between visual areas 17 and 18a of the rat studied in vitro: spatial and temporal organization of functional synaptic responses. Exp Brain Res 1997, 117: 219-241.

[54] Shen W, Liang Z, Chen X, Shou T. Posteromedial lateral suprasylvian motion area modulates direction but not orientation preference in area 17 of cats. Neuroscience 2006, 142: 905-916.

[55] Treue S, Maunsell JHR. Effects of attention on the processing of motion in macaque middle temporal and medial superior temporal visual cortical areas. J Neurosci 1999, 19: 7591-7602.

[56] Reynolds JH, Pasternak T, Desimone R. Attention increases sensitivity of V4 neurons. Neuron 2000, 26: 703-714.

[57] Bullier J, Hupe JM, James, Girard P. The role of feedback connections in shaping the responses of visual cortical neurons. Prog Brain Res 2001, 134: 193-204.

[58] Tomita H, Ohbayashi M, Nakahara K, Hasegawa I, Miyashita Y. Top-down signal from prefront cortex in executive control of memory retrieval. Nature 1999, 401: 600-703.
[59] Gottlieb JP. Smooth eye movements elicited by microstimulation in the primate front eye field. J Physiol 1993, 69: 786-799.

[60] Wurtz RH, Goldberg ME. Activity of superior colliculus in behaving monkey: III. Cells discharging before eye movements. J Neurophysiol 1972, 35: 575-586.

[61] Scheller PH, True SD, Conway JL. Deficits in eye movements following front eye field and superior colliculus ablations. J Neurophysiol 1980, 44: 1175-1189.

[62] Wardak C, Olivier E, Duhamel JR. Sacadic target selection deficits after intraparietal area inactivation in monkeys. J Neurosci 2002, 22: 9877-9884.

[63] Appelle S. Peception and discrimination as a function of stimulus orientation: the "oblique effect" in man and animals. Psychol Bull 1972, 78: 266-278.

[64] Howard IP. Human Visual Orientation. New York: Wiley Press, 1982.

[65] Bonds AB. An "oblique effect" in the visual evoked potential of the cat. Exp Brain Res 1982, 46: 151-154.

[66] Cambell FW, Kulikowski JJ, Levinson J. The effect of orientation on the visual resolution of gratings. J Physiol 1966, 187: 427-436.

[67] Annis RC, Frost B. Human visual ecology and orientation anisotropies in acuity. Science 1973, 182: 729-731.

[68] Timmney BN, Muir DW. Orientation anisotropy: Incidence and magnitude in Gaucasian and Chinese subjects. Science 1976, 193: 699-701.

[69] Maffei L, Campbell FW. Neurophysiological loction of the vertical and horizontal visual coordinates in man. Science 1970, 167: 386-387

[70] Annis RC, Frost B. Human visual ecology and orientation anisotropies in acuity. Science 1973, 182: 729-731.

[71] Timmney BN, Muir DW. Orientation anisotropy: Incidence and magnitude in Gaucasian and Chinese subjects. Science 1976, 193: 699-701.

[72] Chapman B, Bonhoefer CS, Engel SA. Overrepresentation of horizontal and vertical orientation preference in development ferret are 17. Proc Natl Acad U S A 1998, 95: 2609-2615.

[73] Coppola DM, White LE, Fitzpatrick D, Purves D. Unequal representation of cardinal and oblique contours in ferret visual cortex. Proc Natl Acd Sci U S A 1998, 95: 2621-2623.

[74] Coppola DM, Purves HR, McCoy AN, Purves D. The distribution of oriented contours in the real world. Proc Natl Acd Sci U S A 1998, 95: 4002-4006.

[75] Yu H, Shou T. The oblique effect revealed by optical imaging in primary visual cortex of cats. Acta Physiol Sin 2000, 52: 431434.

[76] Furminski CS, Engel SA. The oblique effect in human primary visual cortex. Nat Neurosci 2000, 3: 535-536. 
[77] Wang G, Ding S, Yunokuchi K. Difference in the representation of cardinal and oblique contours in cat visual cortex. Neusci Lett 2003, 338: 77-81.

[78] Huang L, Shou T, Chen X, Sun C, Liang Z. Slab-like functional architecture of higher order cortical area 21 a showing oblique effect of orientation preference in the cat. Neuroimage 2006, 32: 1365-1374.

[79] Montero VM. Comparative studies on the visual cortex. In: Woolsey N (ed.). Cortical Sensory Organization, vol. 2: Multiple visual areas. Clifton, NJ: Humana Press, 1981: 33-81.

[80] Liang Z, Shen W, Shou T. Enhancement of oblique effect in the cat's primary visual cortex via orientation preference shifting induced by excitatory feedback from higher-order cortical area 21a. Neuroscience 2007, 145 (1): 377-383.

[81] Shen W, Liang Z, Shou T. Weakened feedback abolishes neural oblique effect evoked by pseudo-natural visual stimuli in area 17 of the cat. Neurosci Lett 2008, 437: 65-70.

[82] Rockland KS, Ijima H. Calcarine area V1 as a multimodal con- vergence area. Soc Neurosci Sbs 2001, 27: 1342.

[83] Falchier A, Clavagier S, Barone P, Kennedy H. Anatomical evidence of multimodal integration in primary striate cortex. J Neurosci 2002, 22: 5749-5760.

[84] Shams L, Kamitani Y, Thompson S, Shimojo S. Sound alters visual evoked potentials in humans. Neuroreport 2001, 12: 38493852 .

[85] Violentyev A, Shimojo S, Shams L. Touch-induced visual illusion. Neuroreport 2005, 16: 1107-1110.

[86] Singer W. Visual feature integration and the temporal correlation hypothesis. Annu Rev Neurosci 1995: 555-586.

[87] Koffka K. Principles of Gestalt Psychology. New York: Harcourt, 1935.

[88] Engel AK, Kreiter AK, Konig P, Singer W. Synchronization of oscillatory neuronal responses between striate and extrastriate visual cortical areas of the cat. Proc Natl Acad Sci U S A 1991, 88: 6048-6052.

\section{视觉系统中反馈投射的功能作用}

\section{寿天德}

复旦大学脑科学研究中心, 生命科学学院, 视觉研究实验室, 上海 200433

摘要：在神经系统中, 神经元既接受下级结构神经元的投射输入, 又接受上级和同级神经结构神经元的输入, 形 成了极其复杂的神经网络和通路。目前，对于神经系统向前的投射通路的功能作用已有相当深入的了解，但对脑 内反馈的投射通路的功能知之甚少。视觉皮层是研究反馈投射通路的较好模型，其下行反馈的投射涉及注意、搜 索和认知等高级功能。本文主要对有关视觉系统中反馈投射的功能作用做一综述。

关键词：反馈投射；前馈投射；视觉系统；视觉注意；倾斜效应 